\title{
INTERDISCIPLINARIDADE E CURRÍCULO DO CURSO DE DIREITO: UM ESTUDO DE CASO
}

\author{
Renato Duro Dias ${ }^{1}$ \\ Jonas Melo Cruz \\ Vianna ${ }^{2}$
}

\begin{abstract}
Resumo
Esta investigação é um recorte de uma proposta maior que visa compreender o cotidiano do Curso de Direito de uma universidade pública do sul do país. Neste sentido, a pesquisa envolve uma etapa empírica de averiguação das mensagens sociológicas expressas em sala de aula, através de instrumentos qualitativos e entrevista aplicada aos docentes deste curso. Para o presente artigo procurou-se problematizar a interdisciplinaridade em um currículo jurídico através de seus respectivos planos de ensino. Foram analisadas seis disciplinas, escolhidas através de sorteio, distribuídas em três áreas: propedêuticas, dogmáticas e práticas com a finalidade de classificá-las de acordo com os níveis de multi-, inter- ou transdisciplinaridade promovidos pelos elementos expressos nos documentos curriculares.
\end{abstract}

Palavras-chave: Interdisciplinaridade; Integração curricular; Ensino jurídico: Currículo.

\section{INTRODUÇÃO}

Esta investigação é um recorte de uma proposta maior que visa compreender o cotidiano do Curso de Direito de uma Universidade Pública do sul do país. Neste sentido, a pesquisa envolve uma etapa empírica de averiguação das mensagens sociológicas expressas em sala de aula, através de instrumentos qualitativos e entrevista aplicada aos docentes deste curso. Para o presente artigo procurou-se problematizar a interdisciplinaridade em um currículo jurídico através de seus respectivos planos de ensino.

\footnotetext{
${ }^{1}$ Professor Adjunto na Faculdade de Direito da Universidade Federal do Rio Grande - FURG e no Programa de Pós-Graduação em Direito e Justiça Social - Mestrado em Direito da FURG. Coordenador dos Cursos de Graduação em Direito, Coordenador Adjunto do Curso de Especialização em Educação em Direitos Humanos - FURG/UAB, Coordenador do Centro de Referência em Direitos Humanos - CRDH/FURG. E-mail: renatodurodias@gmail.com

2 Bolsista CNPq da Faculdade de Direito, Universidade Federal do Rio Grande. E-mail: jonas.melocruzvianna@gmail.com
} vol.09, nº. 03, Rio de Janeiro, 2016. pp. 
Dessa forma, sustenta-se como fundamental investigar as possibilidades de um currículo que se supõe de coleção e de uma educação jurídica que parece indicar ser especializada, e, por outro lado, analisar se, dentro desta estrutura organizacional de conhecimento, é compatível um modelo mais integrador ou mesmo uma pedagogia que mescle esses níveis e graus nos diferentes contextos curriculares.

Pensa-se que os estudos de Basil Bernstein podem contribuir para as leituras do sistema de organização educacional no qual está inserido o Curso de Direito desta universidade. Defende-se, a partir de Bernstein (1996, p. 295), que as arenas de conflito existentes nas relações de poder e de controle podem potencializar uma mudança.

Num sentido investigativo, os modelos utilizados por Bernstein permitem uma interpretação sobre as práticas de organização, de discursos e de transmissão de que a escola se utiliza, mas o seu próprio estudo possibilita entender a prática pedagógica como algo mais amplo do que a própria instituição escolar. Desta feita, pode-se dizer que os conceitos utilizados por Bernstein permitem descrever uma série de diversas práticas inclusive as que se dão no campo de produção do conhecimento da educação jurídica e do currículo em análise.

Foram analisadas seis disciplinas, escolhidas através de sorteio, distribuídas em três áreas: propedêuticas, dogmáticas e práticas com a finalidade de classificá-las de acordo com os níveis de multi-, inter- ou transdisciplinaridade promovidos pelos elementos expressos nos documentos curriculares. As disciplinas sorteadas em suas respectivas áreas foram: Propedêuticas (Sociologia Geral e História do Direito); Dogmáticas (Constitucional e Direito das Obrigações); Práticas (Prática Jurídica Social I e Oficina de Prática Jurídica I). Cabe ressaltar que todas as disciplinas são referentes ao novo currículo da instituição, vigente a partir do ano de 2013 (dois mil e treze).

Para tal objetivo, utilizou-se, principalmente, dos conceitos de Veiga-Neto (1995) e Bernstein (1990, 1996, 2000), autores que dialogam a integração curricular e a interdisciplinaridade como métodos de repensar a ciência (e as disciplinas) e os modos que as relações de poder e de controle estabelecem instrumentos para a compreensão do processo de controle simbólico que regulam modalidades do discurso pedagógico. As análises ao plano de ensino de cada disciplina foram direcionadas para a prática multi-, pluri-, inter- ou transdisciplinar (UNESCO, 1985; FAZENDA, ; JAPIASSÚ, ; VEIGA-NETO, 1995), de modo que também recorreu-se a diretrizes curriculares nacionais do curso de graduação de direito.

Procurou-se menção às formas de articulação das disciplinas e o meio pelo qual estas se sustentariam, para isso os planos de ensino foram analisados parcialmente, sendo o mesmo vol.09, nº. 03, Rio de Janeiro, 2016. pp. 
composto por oito (08) elementos obrigatórios ${ }^{3}$, sendo respectivamente: características, metodologia e procedimentos, ementa, objetivos, conteúdos, avaliação, bibliografia básica e bibliografia complementar.

Tendo em vista o recorte deste estudo, pressupõe-se que o modelo estardardizado de ensino jurídico aloja as disciplinas em compartimentos, resultado de uma educação e pedagogia segmentada (BERNSTEIN, 1990). Este sistema de operação curricular potencializa as fronteiras entre os conhecimentos disciplinários, seja no aspecto inter, multi ou pluridiciplinar.

O desafio para educação jurídica brasileira, talvez seja repensar de que modo as componentes curriculares dialogam ou não seus conteúdos programáticos. Neste trabalho, escavou-se uma parte de um Currículo Oficial de um Curso de Direito, quiçá como possibilidade vindoura de perceber estes espaços de construção das relações de saber-poder deste artefato cultural do campo jurídico.

\section{O CONTEXTO CURRICULAR}

Segundo as Diretrizes Curriculares Nacionais, os cursos de Direito, em geral, organizamse em três eixos ${ }^{4}$ (art. 5), a saber: o eixo de formação geral (propedêutico), o eixo de formação profissional (técnico-dogmático) e o eixo de formação prática (atuante). A este último ficou dada a tarefa de se integrar aos demais, realizando o que seria uma grande articulação por grandes áreas do conhecimento, explicitadas tanto na normatização nacional (art. 2ª, inciso V e o art. $5^{\circ}$, inciso III da Resolução n 09/2004 CNE/CES) como no currículo do curso em análise

\section{Quadro 1 - Eixos curriculares para os cursos de Direito - Resolução no . 09/2004}

\begin{tabular}{|l|l|l|}
\hline Eixo fundamental & Eixo profissional & Eixo prático \\
\hline & & \\
\hline
\end{tabular}

\footnotetext{
${ }^{3}$ www.sistemas.furg.br

${ }^{4}$ Art. 50 O curso de graduação em Direito deverá contemplar, em seu Projeto Pedagógico e em sua Organização Curricular, conteúdos e atividades que atendam aos seguintes eixos interligados de formação:

I - Eixo de Formação Fundamental tem por objetivo integrar o estudante no campo, estabelecendo as relações do Direito com outras áreas do saber, abrangendo dentre outros, estudos que envolvam conteúdos essenciais sobre Antropologia, Ciência Política, Economia, Ética, Filosofia, História, Psicologia e Sociologia.

II - Eixo de Formação Profissional, abrangendo, além do enfoque dogmático, o conhecimento e a aplicação, [...], dentre outros condizentes com o projeto pedagógico, conteúdos essenciais sobre Direito Constitucional, Direito Administrativo, Direito Tributário, Direito Penal, Direito Civil, Direito Empresarial, Direito do Trabalho, Direito Internacional e Direito Processual; e

III - Eixo de Formação Prática, objetiva a integração entre a prática e os conteúdos teóricos desenvolvidos nos demais Eixos, especialmente nas atividades relacionadas com o Estágio Curricular Supervisionado, Trabalho de Curso e Atividades Complementares.
} vol.09, nº. 03, Rio de Janeiro, 2016. pp. 


\begin{tabular}{|c|c|c|}
\hline Antropologia & Direito Constitucional & Estágio Curricular Supervisionado \\
Ciência Política & Direito Administrativo & Trabalho de Curso \\
Economia & Direito Tributário & Atividades Complementares \\
Ética & Direito Penal & \\
Filosofia & Direito Civil & \\
História & Direito Empresarial & \\
Psicologia & Direito do Trabalho & \\
Sociologia & Direito Internacional & \\
& Direito Processual &
\end{tabular}

Fonte: Autores.

Embora os instrumentos norteadores das políticas curriculares, locais e nacionais indicassem o caminho da integração (articulação), ela de fato talvez nunca tenha ocorrido. Nem entre as disciplinas de conteúdo heterogêneo, nem entre os eixos de formação e tampouco como proposta de uma ideia centralizadora - currículo de integração - em Bernstein (1998).

Estudos de Rodrigues (2003, 2005), Warat (2004) Mondardo et al. (2005) e Dias (2014) constatam a dificuldade entre os docentes dos Cursos de Direito em aderirem às práticas integradoras e/ou interdisciplinares. Verifica-se, também, nessas investigações, que o modo como o ensino jurídico se constitui acabou gerando um espaço de reprodução de conhecimento. Por outro lado, a constituição de áreas extremamente especializadas nas Faculdades de Direito resultou na formação de bacharéis especialistas, o que acabou por afetar a própria formação do docente, já que, no início dos anos 2000, ainda era comum concursos públicos para docente na área do Direito exigindo somente o título de bacharel.

Ao buscar os descritores educação jurídica, interdisciplinaridade e ensino jurídico no Banco de Teses da CAPES encontro-se três (03) trabalhos: duas (02) dissertações de mestrado e uma (01) tese de doutorado, o que indica a relevância da presente investigação.

Quadro 2 - Dissertações e Tese

MORAES, ELCIO ALAUDIO SILVA DE. EDUCAÇÃO JURÍDICA POSITIVISTA E AS DIRETRIZES DO ENSINO JURÍDICO: CURRÍCULO E PRÁTICA PEDAGÓGICA NO CURSO DE DIREITO DA UFPA NO HORIZONTE DAS COMPETÊNCIAS E HABILIDADES ' 01/12/2012 DOUTORADO em DIREITO.

PEREIRA, NEWTON CARLOS FREIRE. EDUCAÇÃO JURÍDICA: O ACESSO À JUSTIC̣A COMO REFERENCIAL DE SUPER AC̣ÃO AO ENSINO DOGMÁTICO ' 01/05/2011 143 f. MESTRADO ACADÊMICO em DIREITO.

PENNA, LEONARDO NOLASCO DE SIQUEIRA. O CONTEXTO DA EDUCACÃO JURÍDICA NO BRASIL PÓS-LDB: A EXPANSÃO DO NÚMERO DE INGRESSANTES E CONCLUINTES E SUA RELAÇÃO COM O NÚMERO DE APROVADOS NO EXAME DA OAB ' 01/03/2012. MESTRADO ACADÊMICO em EDUCAÇÃO.

Fonte: www.bancodeteses.capes.gov.br

Por outro lado, percebe-se que o mercado de trabalho e as provas de qualificação vol.09, nº. 03, Rio de Janeiro, 2016.pp. 
profissional, como são, por exemplo, as aplicadas pela Ordem dos Advogados do Brasil (OAB), exigem bacharéis aptos a perceberem a justiça e a realidade social, mas, estes conhecimentos, por vezes, são avaliados de modo fragmentado, ou seja, pouco dialógicos. Supõe-se que esses padrões avaliativos nacionais da $\mathrm{OAB}$ e dos mais variados concursos das áreas jurídicas (magistratura, defensoria, promotoria) têm ingerido de alguma forma na organização curricular dos cursos de Direito no Brasil. Para esta investigação é impossível traçar o grau e a extensão desta ingerência.

Outro fator que se deve considerar diz respeito ao Exame Nacional de Desempenho de Estudantes do Ensino Superior (ENADE). De alguma forma, as avaliações em larga escala (APPLE, 2009) têm influenciado no padrão de matriz curricular, nos conteúdos e nos mecanismos de proficiência exigidos pelas Faculdades de Direito. Essas relações se tornam mais complexas, principalmente, quando se trata de analisar instituições privadas (BALL, 2010), cujo rankeamento é condição de subsistência num mercado extremamente competitivo.

Trata-se de um tipo diferente de Economia do Conhecimento, onde percebemos o valor monetário e a lucratividade da educação de forma clara e direta. Isso apresenta tanto oportunidades como perigos para os governos nacionais. Essas formas institucionais de Ensino Superior podem propiciar meios rápidos e baratos de capacitação da força de trabalho local até os níveis exigidos pela economia do conhecimento, ao mesmo tempo em que satisfaz a crescente demanda por acesso ao ES, especialmente aquelas instituições que oferecem certificações de reconhecimento internacional e potencial de entrada no mercado de trabalho global. (BALL, 2010, p. 495).

Entende-se que os exames nacionais merecem destaque, porém se considera que esses elementos não sejam passíveis de serem analisados, dada as limitações e recortes dessa investigação.

Em outro sentido, a integração e a interdisciplinaridade são temas reincidentes das Diretrizes Curriculares Nacionais para os cursos de Direito, senão vejamos a Resolução nº 09, de 2004, CNE, art. $2^{\circ}$, parágrafo $1^{\circ}$ :

$\S 1^{\circ} \mathrm{O}$ Projeto Pedagógico do curso, além da clara concepção do curso de Direito, com suas peculiaridades, seu currículo pleno e sua operacionalização, abrangerá, sem prejuízo de outros, os seguintes elementos estruturais: [...] IV - formas de realização da interdisciplinaridade; $\mathrm{V}$ - modos de integração entre teoria e prática; [...] VII - modos da integração entre graduação e pós-graduação, quando houver; VIII - incentivo à pesquisa e à extensão, como necessário prolongamento da atividade de ensino e como instrumento para a iniciação científica; IX - concepção e composição das atividades de estágio curricular supervisionado, suas diferentes formas e condições de realização, bem como a forma de implantação e a estrutura do Núcleo de Prática Jurídica; (grifo nosso)

De acordo com Fazenda (1992), o termo integração se diferencia de interdisciplinaridade na medida em que aquela seria objetivo final desta. Assim, para Fazenda (1992), a interdisciplinaridade é vista como uma atitude de diálogo e de interação entre conhecimentos vol.09, nº. 03, Rio de Janeiro, 2016. pp. 
(disciplinas) heterogêneos e acaba por ser um mecanismo para se alcançar a integração. Para Veiga-Neto (1995), a interdisciplinaridade estabelece um novo nível de conhecimentos, já que o nível de relacionamentos entre as matérias e/ou disciplinas é ampliado. Contudo, tanto nas Diretrizes Curriculares, como no PPP do curso em análise, ainda se observam cotidianamente a fragmentação e a especialização do conhecimento.

Num primeiro momento selecionaram-se alguns excertos dos planos em análise que dão conta da falta de elementos indicadores de caráter meramente formal. Embora não seja este o principal objeto de análise, entende-se imprescindível problematizar, previamente, esta incompletude dos elementos obrigatórios dos planos de ensino, bem como a ausência de consenso conceitual acerca destes elementos como forma de representar a dificuldade do docente, quando da elaboração do plano. Pode-se elencar, exemplificativamente, o ocorrido em duas disciplinas: História do Direito e Oficina de prática jurídica I.

\section{HISTÓRIA DO DIREITO \\ Metodologia e procedimentos}

A metodologia será feita com provas e seminários, 7,0 pontos e 3 pontos.

\section{HISTÓRIA DO DIREITO \\ Avaliação}

A avaliação dos discentes será realizada com base em provas e seminários, a prova valendo 7 pontos e o seminário valendo 3 pontos.

Neste primeiro caso, nota-se uma duplicação conceitual no elemento obrigatório avaliação. Veja-se que o docente ao preencher o formulário, confunde metodologia com avaliação. Embora se possa argumentar que o próprio PPP do Curso (2013) não elucide claramente os possíveis mecanismos de avaliação, bem como as metodologias a serem aplicadas, percebe-se que o plano em análise não elenca a metodologia e os procedimentos da prática pedagógica docente, e mais, produzindo uma confusão terminológica, que inclusive afeta o discente.

Por outro lado, embora se estabeleçam as pontuações máximas e os tipos de avaliação, também fica silente o plano quanto aos critérios de cada avaliação, inclusive, por exemplo, não sendo explicitado o caráter da "prova", se escrita ou oral. Enfim, com estes dois exemplos, 
percebeu-se a ausência de explicitação dos critérios avaliativos e metodológicos, o que pode se traduzir numa dificuldade na relação discursiva aluno-professor.

Com relação ao caso da Oficina de Prática Jurídica I ocorre situação semelhante, no entanto agora a questão envolve os temas ementa e conteúdos programáticos, o que, também, demonstra uma inoperância do docente com a elaboração do plano.

\section{OFICINA DE PRÁTICA JURÍDICA I \\ Ementa}

A disciplina tem por objetivo o exercício da prática jurídica simulada, abrangendo elaboração de atos extrajudiciais e de peças processuais de natureza cível, abrangendo os distintos procedimentos judiciais pertinentes, incluindo especialmente petição inicial com antecipação de tutela, Agravo, Contestação, Réplica, Sentença, Apelação, Recurso Especial, Recurso Extraordinário simulando a atuação nas diferentes profissões jurídicas, notadamente as de Advogado, Magistrado e membro do Ministério Público.

\section{OFICINA DE PRÁTICA JURÍDICA I}

Conteúdos

Pratica jurídica simulada : atos extrajudiciais, peças de natureza cível, abrangendo os distintos procedimentos judiciais, simulação da atuação das diferentes profissões jurídicas na área cível. elaboração de peças processuais em temas e procedimentos diferenciados no âmbito do processo civil, tais como : Petição inicial com antecipação de tutela, Agravo de instrumento, Contestação, Réplica, Sentença, Apelação, Recurso Especial, Recurso Extraordinário.

Como se notou nos exemplos acima há uma confusão em relação aos critérios do plano de ensino. No primeiro caso, Metodologia e procedimentos foram explicados de maneira muito similar ao método de avaliação, apesar da proximidade que possa existir, são tópicos que mereceriam explicação diferenciada; no segundo, a questão remete a ementa e ao conteúdo programático.

Por outro lado, da análise preliminar, percebe-se que alguns planos de ensino utilizam adequadamente. Veja-se o exemplo da disciplina de Sociologia Geral, em que tal explicação foi suficientemente clara para a percepção da mensagem sociológica presente (BERNSTEIN, 1990), principalmente com relação à disposição das aulas.

\section{SOCIOLOGIA GERAL \\ Metodologia e Procedimentos}

Aulas dialogadas, estudos em grupos, seminários, consultas bibliográficas. Recursos: material produzido pelo professor, livros, periódicos científicos e artigos de revistas e jornais. Leitura de textos na biblioteca para atividades em aula e para trabalhos complementares. Trabalhos individuais e em grupo. Consultas à internet.

Analisou-se, também, no Plano Político Pedagógico do Curso de Direito de 2013 
critérios para o quesito "processos de avaliação", porém no mesmo só foram encontrados dois sub-tópicos: critérios e sistemas de avaliação. No qual, respectivamente, estabelecem: provas para disciplinas teóricas e tarefas para disciplinas práticas; e as fórmulas para o cálculo das notas com ou sem exame, bem como a porcentagem mínima de presença em cada disciplina. Assim, parece ficar a critério do professor a interpretação do que consiste uma "prova”, ou seja, não existe nenhum indicativo de sistemas de avaliação ou padrões possíveis. Neste sentido, entende-se que tanto o professor quanto o aluno podem usar como referência; um como método de exigência e o outro como meio mínimo de potencializar suas habilidades e competências.

No caso da disciplina Oficina de Prática Jurídica I o quesito conteúdo ficou prejudicado ao receber explicação similar ao da ementa, havendo carência de orientação referente ao recorte e o ramo de conhecimento que será utilizado, ou seja, uma "tábua" de conteúdos e saberes, intrínsecos ao desenvolvimento e aprendizagem da/na disciplina.

Em outro caso, os conteúdos da disciplina foram bem delimitados, tornando claro, preciso e discriminado, o conjunto de aportes teóricos que o professor pretende alcançar seus objetivos ao longo do ano. Segue como exemplo um recorte de conteúdo bem delimitado.

\section{DIREITO CONSTITUCIONAL \\ Conteúdos}

UNIDADE 1

1. SOCIEDADE, ESTADO E DIREITO. TEORIA GERAL DO ESTADO

2. ELEMENTOS CONSTITUTIVOS DO ESTADO - SOBERANIA. NASCIMENTO, EXTINÇÃO E ORIGEM DO ESTADO, TIPOS DE ESTADO.

UNIDADE 2

1. ESTADO E CONSTITUIÇÃO. FORMAS DE ESTADO E DE GOVERNO

2. EVOLUÇÃO DO CONSTITUCIONALISMO NO MUNDO E NO BRASIL UNIDADE 3

1. O PODER CONSTITUINTE - NATUREZA E TITULARIDADE - TEORIAS.

2. DIREITO CONSTITUCIONAL - POSIÇÃO NO QUADRO GERAL DO DIREITO . FONTES, MÉTODOS E INTERPRETAÇÃO 


\section{A TEORIA BERNSTEINIANA}

Sendo o conhecimento educacional um importante regulador da estruturação da experiência, Bernstein (1990a) considera que se deve analisar como ocorre a transmissão formal do conhecimento educacional. Para tal, assume que o processo educativo mantém e altera as formas de experiência, de identidade e de relação social.

A análise bernsteiniana centra-se nas estruturas formais da transmissão educacional. Considerando que o conhecimento formal é realizado através de três sistemas de mensagem, currículo, pedagogia e avaliação (BERNSTEIN, 1990 b), Com base nessa distinção e usando os conceitos de classificação e de enquadramento, o sociólogo inglês apresenta uma tipologia de códigos de conhecimento educacional, princípios subjacentes aos currículos. Estas estruturas curriculares, assim, são influenciadas por estes sistemas de codificação, que segundo Bernstein (1990a) determinam os mecanismos de poder e controle dentro da escola/universidade.

Para compreender Basil Bernstein, é fundamental apropriar-se dos conceitos por ele utilizados. Bernstein problematizou em seus estudos sociológicos uma ampla gama de categorias de análise dentre as quais podemos referenciar: poder e controle; enquadramento e classificação; democracia; identidades; os códigos e o discurso e o dispositivo pedagógicos (BERNSTEIN, 1996).

É importante também frisar que a teoria sociológica de Bernstein dialoga com as relações macro e micro, o que possibilita entender a escola e o que se passa dentro dela correlacionado-a com os sistemas externos, nitidamente os aspectos econômicos, sociais e culturais da sociedade. Por essa razão, sua teoria tem sido um constante desafio para os mais variados pesquisadores, sejam eles do campo educacional ou de outras áreas do conhecimento.

The model we have developed may be used to generate relations between agencies and relationships within agencies, whether these be at so-called 'macro' or 'micro' levels. ' (BERNSTEIN, 1990, p. 47).

No que também se refere à possibilidade das investigações potencializarem as interações entre o macro e o micro nível.

The paper does show that the basic underlying logic of this and other papers can deal with the question of content, as well as linking macro and micro levels of analysis. ${ }^{6}$ (BERNSTEIN, 1990, p. 77).

Nesse aspecto, é preciso dizer que os contextos locais são afetados pelo campo

\footnotetext{
${ }^{5}$ Em tradução livre: "O modelo desenvolvido pode ser utilizado para gerar relações entre agências e os relacionamentos dentro das agências, quer estes sejam chamados ' macro' ou níveis 'micro'."

${ }^{6}$ Em tradução livre: "O estudo mostra que a lógica básica subjacente desta e de outras investigações pode lidar com a questão do conteúdo, bem como a ligação macro e micro em níveis de análise.” 
econômico e de controle simbólico, implicando uma dupla relação (BERNSTEIN, 1996, p. 278). As teorias, as práticas e as relações sociais nesses campos exercerão uma influência sobre o discurso a ser transmitido e sobre como eles são transmitidos, tanto sobre o que quanto sobre o como do discurso pedagógico. As exigências de treinamento dos agentes dominantes (especialmente dos agentes dominantes do campo do controle simbólico) influenciarão o que e o como.

Pensa-se que uma teoria deve ser considerada sempre como um ponto de partida e nunca de chegada, para a compreensão de seus contributos e para o aprofundamento das questões teóricas a que ela nos remete.

Outra questão fundamental é tentar compreender qual "a filiação" a que Bernstein está vinculado. Seus estudos começam e dão origem ao que foi chamado de Nova Sociologia da Educação, por essa razão suas pesquisas acabaram por se constituir em uma inovadora leitura do campo pedagógico e dos discursos engendrados na escola (DIAS, 2014).

Bernstein baseou parte de seu estudo nos trabalhos de Durkheim cuja relevante contribuição aponta para a temática da divisão social do trabalho (BERNSTEIN, 1996, p. 211). De Durkheim, Bernstein se apropriou do conceito de coesão social e solidariedade social, para poder entender as duas formas de organização societárias apresentadas por aquele autor e subdividas em mecânica e orgânica. Entende-se que, ao analisar essas estruturas, Bernstein consegue perceber na forma de solidariedade orgânica a semelhança da estrutura social vigente. Por essa leitura, parece-me que os códigos pedagógicos criados por Bernstein nos seus inúmeros estudos remontam aos códigos e regras de condutas, aos direitos e deveres e as normas jurídicas que foram delineadas no trabalho de Durkheim.

From Durkheim (1938) we interpret the Trivium (logic, grammar, and rhetoric) as constituting the discursive principles of mechanical solidarity, subject to shifts of internal emphasis and conflicts arising out of the developing bourgeoisie; and the Quadrivium, its specialized, separated discourses, astronomy, arithmetic, geometry, and music, pointing to the development of the historically much later organic solidarity. Durkheim (1925), a set of lectures for schoolteachers, is concerned essentially with the regulative discourse of the school. Durkheim (1938), a set of lectures for aggregation candidates, analyses the history and development between disciplines, practices, and moralities of education, and their external regulations. Durkheim concerned himself, in these lectures, with two fundamental questions: 'How the institution of the school came to be formedand how these schools came to be differentiated from the Church.' However, the context Durkheim created for himself in answering these questions was nothing less than an institutional history of the forms and 
content of education.7 (BERNSTEIN, 1990, p.183).

Visualiza-se, na obra de Bernstein, outra significativa contribuição, a que diz respeito ao entrelaçamento da educação e da democracia. Ele consegue dar luz a três níveis fundamentais de reconhecimento desse interrelacionamento: individual, social e político. Percebe-se que, para Bernstein, a educação torna-se um lócus potencializador da apropriação individual do conceito de democracia e da sua construção coletiva e indispensavelmente política. Isso porque o autor se dá conta de que a escola, por vezes, reflete imagens das relações desiguais de distribuição dentro da sociedade (SANTOS, 2003).

Ainda sobre outra face, os estudos sobre comunicação pedagógica por Basil Bernstein (1996) possibilitam uma potencial proposta de mudança. O próprio autor vai elucidar essa proposição ao final da sua principal obra traduzida para o português, quando argumenta que o discurso pedagógico e o dispositivo pedagógico, bem como seu modelo, carregam em si um forte potencial de mudança (BERNSTEIN, 1996).

Change, then, is a consequence of the inner potential of the device and the arena of conflict which is the social base of its realizations. ${ }^{8}$ (BERNSTEIN, 1990, p. 182).

A partir da forma de relação que os conteúdos de estatuto mais elevado mantêm entre si, podem se definir dois tipos fundamentais de currículo: currículo de coleção e currículo de integração.

Num currículo de coleção, o conhecimento está organizado em conteúdos isolados, cada professor no seu campo pode, dentro de certos limites prescritos, seguir um caminho próprio. Neste currículo, a pedagogia é didática e os critérios de avaliação independentes. As rubricas programáticas de cada conteúdo estão nas mãos de quem ensina e de quem avalia o que vai permitir a existência de diferenças consideráveis, quer na prática de ensino, quer nas formas de avaliação. (BERNSTEIN, 1998, p. 198)

De acordo com Bernstein, no currículo de integração, os vários conteúdos estão subordinados a uma idéia central que, reduzindo o isolamento entre eles, os agrega num todo mais amplo.

\footnotetext{
${ }^{7}$ Em tradução livre: "De Durkheim (1938) interpretamos o Trivium (lógica, gramática e retórica) como constituindo os princípios discursivos de solidariedade mecânica, sujeitas a mudanças de ênfase interna e conflitos decorrentes da burguesia em desenvolvimento e o Quadrivium, a sua especializada, com discursos separados, astronomia, aritmética, geometria, e música, que historicamente aponta para o desenvolvimento, muito mais tardio, da solidariedade orgânica. Durkheim (1925), em um conjunto de palestras para professores, aponta a causa, essencialmente, para o discurso regulador da escola. Durkheim (1938), em um conjunto de palestras para os candidatos de magistério, analisa a história e desenvolvimento entre as disciplinas, práticas e moralidades de educação, e seus regulamentos externos. Durkheim preocupou-se, nessas palestras, com duas questões fundamentais: 'Como a instituição da escola veio a ser formada e como essas escolas passaram a ser diferenciada da Igreja.' No entanto, o contexto que Durkheim criou para responder a essas perguntas não era nada menos de uma história institucional das formas e conteúdos da educação."
} 
Uma vez que num currículo de integração o conhecimento está organizado em conteúdos abertos que se inter-relacionam em torno de uma idéia central, integradora, os diferentes professores encontram-se envolvidos numa tarefa partilhada, o que conduz à necessidade de uma pedagogia e de um estilo de exame comuns. Para além de ter de haver uma prática pedagógica comum, esta deve centrar-se no modo como o conhecimento é adquirido e não nos estados do conhecimento. (BERNSTEIN, 1998, p. 199)

Por isso, um código de conhecimento educacional transforma-se num princípio modelador de determinado currículo e, em decorrência, modelador de sua pedagogia e de sua avaliação. Para poder analisar cada uma das tipologias de códigos previstas na teoria bernsteiniana, é fundamental diferenciar classificação de enquadramento. Bernstein, a partir dos códigos de produção dos recursos físicos, afirmava que "as relações entre as várias categorias de produção" podem ser vistas em termos de classificação (forte ou fraca) enquanto que "a forma de comunicação constituída pelo sistema de categorias de modo de produção" pode ser pensada em termos de enquadramento (forte e fraco) (BERNSTEIN, 1996, p. 76-77).

Para compreender a noção de código, Bernstein (1996) apresenta-nos um modelo em que discute os códigos específicos. Para ele um código regula as relações entre contextos e através dessas, as relações interiores ao contexto. Por essa razão, o código deve gerar princípios que distingam o que se relaciona ao entre e o que se refere ao interior de um contexto (dentro). A esses princípios Bernstein (1996, p. 30) denomina regras de reconhecimento (recognition) e regras de realização (realization). No modelo de Bernstein (1996, p. 31), veem-se quais os significados (meanings) relevantes que são transformados em orientações específicas a estes significados. De acordo com a teoria sociológica bernsteiniana, o entre implica poder e o dentro implica controle. Para poder, Bernstein estabelece como regulação a classificação (classification) e, para controle, o enquadramento (framing). Em Bernstein, o que conta como produção textual depende do nível de análise entre estas regras e orientações (1996, p. 13).

Neste sentido, a teoria bernsteiniana torna-se potente para desvelar quais os princípios e códigos (coleção ou integração) subjascentes no Currículo Oficial de um Curso de Direito.

\section{ANÁLISE DAS DISCIPLINAS}

$\mathrm{Na}$ análise foco desta investigação, primeiramente, procurou-se indícios diretos referentes

\footnotetext{
${ }^{8}$ Em tradução livre: "A mudança, então, é uma consequência do potencial interior do dispositivo e da arena de conflito, que é a base social de suas realizações."
} 
à forma de articulação da disciplina com outras (interdisciplinaridade), de maneira que esta fosse expressa no plano de ensino. Cabe ressaltar que tal análise é materialmente limitada pelo plano de ensino. No segundo momento, quando da pesquisa de campo (etapa seguinte a esta investigação) se reservará um questionário aos respectivos professores, o qual será possível comparar tais respostas e a análise do plano de ensino, culminando numa futura análise de sala de aula.

Atualmente, uma das questões suscitantes envolve saber qual ou quais modelos a estrutura do conhecimento deve se organizar, disciplinar ou temático (inter, pluri, multi ou transdisciplinar). Durante uma boa parte da história e do percurso na escola, não se questionava a importância de existirem disciplinas e de conhecimentos especializados sob a forma de disciplinar. Gusdorf afirmava, na obra de Japiassu, que a inteligência humana era, essencialmente, interdisciplinar (JAPIASSU, 1976).

$\mathrm{Na}$ década de 1970, surgem investigações demonstrando que o conhecimento disciplinário, muitas vezes fragmentado e isolado, não poderia conduzir a emancipação ou a educação transformada. Aparecem, assim, os estudos inter e pluridisciplinares.

No Brasil, algumas idéias européias sobre a questão disciplinar, principalmente as de GUSDORF, JANTSCH e PIAGET, tiveram aceitação geral graças, sobretudo, à produção filosófica de Hílton JAPIASSU durante os anos 70 (veja, especialmente, JAPIASSU, 1976, 1977). Constata-se que, no próprio título do seu mais importante livro sobre o assunto (JAPIASSU, 1976), o autor refere-se a "patologia do saber"... Nessa busca da restauração da aliança perdida de que nos falou GUSDORF no próprio prefácio do livro de JAPIASSU, esse autor identifica quatro níveis progressivos, que vão da multidisciplinaridade, passam pela pluri e interdisciplinaridade e chegam à transdisciplinaridade. Mesmo reconhecendo a polissemia dos termos acima, é possivel sumariar seus significados principais, sobretudo nas acepções que circularam e ainda circulam no discurso pedagógico brasileiro. (VEIGANETO, 1995, p. 109) (grifado no original).

Um dos precursores no Brasil, Japiassu, em Interdisciplinaridade e patologia do saber (1976, p. 74), conceitua-a afirmando que "A interdisciplinaridade caracteriza-se pela intensidade das forças entre os especialistas e pelo grau de integração real das disciplinas no interior de um mesmo projeto de pesquisa."

Baseado em uma proposta para pensar as múltiplas formas (níveis) sobre a questão disciplinar a UNESCO/ONU, realizou em 1985, um seminário que acabou por gerar um conjunto de aportes teóricos sobre a interdisciplinaridade, especialmente no campo da educação (UNESCO, 1986).

Para a UNESCO (1986, p.06),

Le concept d'interdisciplinarité se situant sur le plan épistémologique, on peut vol.09, nº. 03, Rio de Janeiro, 2016. pp. 
considérer qu'il se réfère à la coopération de disciplines diverses, qui contribuent à une réalisation commune et qui, par leur association, permettent l'émergence et le progrès de nouveaux savoirs.9

Embora entenda como uma atitude, Fazenda (1992a) em Fundamentos de uma prática interdisciplinar a partir da tese - interdisciplinaridade - um projeto em parceria, aproxima-se do conceito apontado pela UNESCO (1986).

\begin{abstract}
Entendemos por atitude interdisciplinar, uma atitude frente a alternativas para conhecer mais e melhor; atitude de espera frente aos atos não consumados, atitude de reciprocidade que impele à troca, que impele ao diálogo, ao diálogo com pares anônimos ou consigo mesmo, atitude de humildade frente à limitação do próprio saber, atitude de perplexidade frente à possibilidade de desvendar novos saberes, atitude de desafio frente ao novo, desafio de redimensionar o velho, atitude de envolvimento e comprometimento com os projetos e com as pessoas neles envolvidas, atitude pois, de compromisso em construir sempre de melhor forma possivel, atitude de responsabilidade, mas, sobretudo, de alegria, de revelação, de encontro, enfim, de vida. (FAZENDA, 1992a, p, 09).
\end{abstract}

\title{
As propedêuticas
}

Das disciplinas propedêuticas, Sociologia Geral e História do Direito, apenas a disciplina Sociologia Geral enunciou a interdisciplinaridade claramente em seu plano de ensino, em consonância com o Parecer CES/CNE no 146/02, a Resolução CES/CNE nº 09/04 e com o Plano Político Pedagógico. Sendo um exemplo de interdisciplinaridade ${ }^{10}$ num sentido externo (RODRIGUES, 2000), ou seja, do direito com outras áreas do conhecimento, enquanto que para Veiga-Neto (1995), interdisciplinaridade compreende a formação de um novo conhecimento a partir da interação de duas disciplinas.

\section{SOCIOLOGIA GERAL}

Objetivos

Apresentar aos alunos a perspectiva sociológica de análise sobre os fenômenos sociais e jurídicos, discutindo a relação entre as normas jurídicas e a estrutura social, demonstrando a viabilidade e a necessidade de uma visão interdisciplinar para a formação dos operadores do direito, que leve em conta não apenas a normatividade estatal, mas também a gênese, a eficácia e os efeitos das

normas na sociedade. Como resultado, espera-se que os alunos adquiram condições para desenvolver uma abordagem do fenômeno jurídico a partir da perspectiva sociológica, utilizando elementos conceituais das principais teorias sociológicas clássicas e contemporâneas.

\footnotetext{
${ }^{9}$ Em tradução livre: "O conceito de interdisciplinaridade se situa sobre o plano (nível) epistemológico, o qual se pode considerar que se refere à cooperação de diversas disciplinas, que contribuem para uma compreensão comum e, por associação, permitem o surgimento e o desenvolvimento de novos conhecimentos (saberes)."

${ }^{10}$ A interdisciplinaridade objetiva a correlação das disciplinas de maneira a originar novas disciplinas ou até mesmo novas áreas do conhecimento (RODRIGUES, 2000).
} 
A segunda disciplina, História do Direito, enunciou um conceito de multidisciplinaridade, ${ }^{11}$ que para Veiga-Neto (1996), representa disciplinas que se justapõe, porém não dialogam.

\section{HISTÓRIA DO DIREITO \\ Objetivos}

O presente curso pretende discutir e aprofundar uma compreensão multidisciplinar do complexo desenvolvimento diacrônico e sincrônico do direito. Para isso, se faz necessário uma releitura do discurso histórico tradicional com vistas a dotar-lhe de operacionalidade crítica e reflexiva, o que requer a análise de algumas teorias da história e de sua aplicação particular no campo da história do direito fugindo dos cânones da historiografia oficial.

Após estas constatações iniciais procurou-se a sustentação de tais afirmações de interdisciplinaridade e multidisciplinaridade nos próprios planos de ensino, a fim de constatar a maneira pela qual esta seria possível. A disciplina de Sociologia Geral encontra-se dentro do currículo do curso de direito e se compromete a complementar a formação jurídica, numa perspectiva sociológica, dialogando com conhecimentos externos a disciplina, porém presentes no currículo. Uma proposta complexa como demanda seu respectivo plano de ensino:

\section{SOCIOLOGIA GERAL \\ Conteúdos programáticos}

1 O pensamento social e teorias sociológicas clássicas: sociedade e Estado

1.1 Introdução: contexto histórico do surgimento da sociologia, Iluminismo, Positivismo;

1.2 Sociedade, Estado e Estado de direito: as teorias do Estado, poder e democracia

1.3 A sociedade harmônica: o funcionalismo de Durkheim.;

1.4 Racionalização e instituições: Weber e Parsons;

1.5 Marx e a contradição interesses individuais, sociais e transformação;

2. A sociedade da época contemporânea, teorias, o conhecimento e novos problemas para direito

3.1 Estado e sociedade. Teorias, conceitos, problemas.

3.2 Teorias contemporâneas sobre a realidade social.

3.3 A crise dos Estados nacionais na transição pós-moderna: sintomas e perspectivas.

Constatou-se inúmeras interações possíveis entre o conteúdo de Sociologia Geral com outras disciplinas do direito como Constitucional, Ciência Política, Estado e Constituição, Dogmática Jurídica e, acima de tudo, permear a Filosofia e os fundamentos do atual positivismo jurídico, contudo a mesma não detém nenhuma referência bibliográfica normativa, contando

\footnotetext{
${ }^{11}$ A multidisciplinaridade trabalha as disciplinas de maneira não-linear entre si, objetivando um conhecimento sólido e sem correlação (VEIGA-NETO, 1996).
} 
apenas com referências dentro da sua área de conhecimento e filosóficas.

\section{SOCIOLOGIA GERAL \\ Bibliografia Básica}

MARTINS, Carlos. O que é Sociologia.: São Paulo: Editora Brasiliense, 1985. ISBN.

CARNOY, Martin. Estado e teoria politica / Martin Carnoy - Campinas : Papirus, 1990. ISBN.

DURKHEIM, Émile. As regras do método sociológico / Émile Durkheim; tradução de Pietro Nassetti. São Paulo : Martin Claret, 2004. ISBN.

QUINTANEIRO, Tania. Um toque de classicos : Marx, Durkheim e Weber / Tania Quintaneiro, Maria Ligia de Oliveira Barbosa, Marcia Gardenia Monteiro de Oliveira. - Belo Horizonte : UFMG, 2003. ISBN

WEBER, Max. A ética protestante e o espírito do capitalismo / Max Weber; tradução Pietro Nassetti. São Paulo : Martin Claret, 2007. ISBN.

\section{SOCIOLOGIA GERAL}

Bibliografia Complementar

FOUCAULT, Michel. Microfísica do poder / Michel Foucault; organização, introdução e revisão técnica de Roberto Machado. - Rio de Janeiro : Graal, 1979. - ISBN . Müller. São Paulo : Martin Claret, 2008. ISBN .

MARX, Karl. A ideologia alemã : Feuerbach - a oposição entre as concepções materialista e idealista / Karl Marx, Friedrich Engels ; tradução de Frank Müller. São Paulo : Martin Claret, 2008. ISBN.

OLIVEIRA, F. \& PAOLI, Maria Célia (orgs). Os sentidos da democracia. Petrópolis : vozes, 1999. ISBN.inho. Rio de Janeiro: Civilização Brasileira, 1989. ISBN.

GRAMSCI, Antonio. Concepção dialética da história / Antonio Gramsci ; tradução de Carlos Nelson Coutinho. Rio de Janeiro: Civilização Brasileira, 1989. ISBN.

A segunda disciplina, História do Direito, enuncia a multidisciplinaridade, demonstrando uma consciência crítica do professor, apesar de sustentar indícios de diálogo externo e interno com o direito, no seu respectivo conteúdo, permanece ainda dentro do conceito de multidisciplinaridade, não atendendo "conceitualmente" ao Parecer e a Resolução do CES/CNE, porém não significa falta de diálogo com outras disciplinas ao ponto de criar novos conhecimentos. Sendo, porém, a única disciplina, das analisadas, a citar o Ensino Jurídico em seu conteúdo. 


\section{Os conteúdos serão respectivamente os seguintes:}

\section{Conteúdos}

Na Unidade I- O Direito nas sociedades arcaicas, na Antiguidade Oriental e Ocidental.

Na Unidade II- Será apresentado o Direito Romano

$\mathrm{Na}$ Unidade III- O direito emergente das revoluções e do Estado Moderno. O Código Civil Napoleônico, o surgimento dos direitos humanos, o constitucionalismo e os conflitos decorrentes da formação do colonialismo Europeu, do etnocentrismo e do eurocentrismo.

Na Unidade IV- O Direito no Brasil incluirá o período colonial, o período do império, o direito republicano. O Ensino Jurídico no Brasil. E a relação deste período com as questões da escravidão, a questão indígena no Brasil e na América Latina.

$\mathrm{Na}$ Unidade V- Nesta última fase será destacada a questão do golpe civil-militar e da redemocratização.

Esta disciplina tende a um caráter interdisciplinar, pois a mesma parte de uma visão histórica do direito brasileiro e geral (“sociedades arcaicas”, romano, germânico, indígena ${ }^{12}$ ). Além disto, cabe ressaltar os apontamentos para fatos históricos que influenciariam diretamente o desenvolvimento da sociedade brasileira atual e seu ordenamento jurídico, cabe ressaltar o colonialismo, a escravidão e o golpe civil-militar. Desta maneira percebeu-se que tais apontamentos encontram referências tanto na bibliografia básica como na complementar, apresentando um permeamento interdisciplinar interno e externo ao direito, áreas do conhecimento como a história brasileira e geral, filosofia, sociologia e outras. Segue as tabelas com as respectivas bibliografias.

\section{HISTÓRIA DO DIREITO}

Bibliografia Básica

CASTRO, Flávia Lages de. Historia do direito geral e Brasil / Flávia Lages de Castro. - Rio de Janeiro : Lumen Juris, 2011.

Fundamentos de história do direito / organização Antonio Carlos Wolkmer. - Belo Horizonte : Del Rey, 2011. Curitiba: Juruá, 2000.

COLAÇO, Thais Luiza. "Incapacidade" indígena : tutela religiosa e violação do direito guarani pré-colonial nas missões jesuíticas/ Thais Luiza Colaço. - Curitiba: Juruá, 2000.

MACIEL, José Fábio Rodrigues. História do direito / [autor] e coordenador José Fábio Rodrigues Maciel, Renan Aguiar.- São Paulo : Saraiva, 2011.

LOPES, José Reinaldo de Lima. O direito na historia : lições introdutórias / José Reinaldo de Lima Lopes.- São Paulo : Atlas, 2008.

GODOY, Arnaldo Sampaio de Moraes. Direito nos Estados Unidos / Arnaldo Sampaio de Moraes Godoy.- Baurueri, SP : Manole, 2004.

\footnotetext{
12 Termo utilizado no plano de ensino da referida disciplina, porém o termo povos originários seria mais
} apropriado. 


\section{HISTÓRIA DO DIREITO \\ Bibliografia Complementar}

COLAÇO, Thais Luiza. "Incapacidade" indígena : tutela religiosa e violação do direito guarani pré-colonial nas missões jesuíticas/ Thais Luiza Colaço. - Curitiba: Juruá, 2000.

Direito e justiça na América indígena : da conquista a colonização / organizador Antonio Carlos Wolkmer. - Porto Alegre : Livraria do Advogado, 1998.

DAVID, Rene. Os grandes sistemas do direito contemporâneo / Rene David; tradução Herminio A. Carvalho.- São Paulo : Martins Fontes, 1998.

DUCOS , Michèle. Roma e o direito / Michèle Ducos; tradução Silvia Sarzana, Mário Pugliesi Netto. - São Paulo : Madras, 2007.

\section{As dogmáticas e a interdisciplinaridade}

As disciplinas dogmáticas sorteadas para análise foram Direito Constitucional e Direito das Obrigações, ambas não enunciam a interdisciplinaridade, contudo, no decorrer da análise, apresentaram algumas características interessantes em seus respectivos planos de ensino.

Primeiramente analisar-se-á a disciplina de Constitucional. Apesar de não enunciar a interdisciplinaridade, percebem-se indícios de interdisciplinaridade através da ementa e do conteúdo da disciplina, pois ao abordar temas como Estado, Sociedade e Elementos Constitutivos do Estado aproximou-se de uma fronteira muito tênue com algumas disciplinas propedêuticas, como: Ciência Política e Organização do Estado (CPEC), Sociologia e História do Direito.

\section{CONSTITUCIONAL}

Ementa

A constituição brasileiro vigente: princípios fundamentais. Organização do Estado. Organização dos poderes. Defesa do Estado das instituições democráticas. Tributação e orçamento. Ordem econômica e financeira. Dos direito e garantias fundamentais na Constituição Federal brasileira de 1988: Direitos e deveres individuais e coletivos, sociais. Da nacionalidade e políticos. Ordem social. Disposições gerais e transitórias. Constituição, meio ambiente e desenvolvimento.

\section{CONSTITUCIONAL \\ Conteúdo ${ }^{13}$ \\ UNIDADE 1}

1. SOCIEDADE, ESTADO E DIREITO. TEORIA GERAL DO ESTADO

2. ELEMENTOS CONSTITUTIVOS DO ESTADO - SOBERANIA. NASCIMENTO,

\footnotetext{
${ }^{13}$ Recorte do conteúdo do plano de ensino de Constitucional.
} vol.09, nº. 03, Rio de Janeiro, 2016. pp. 


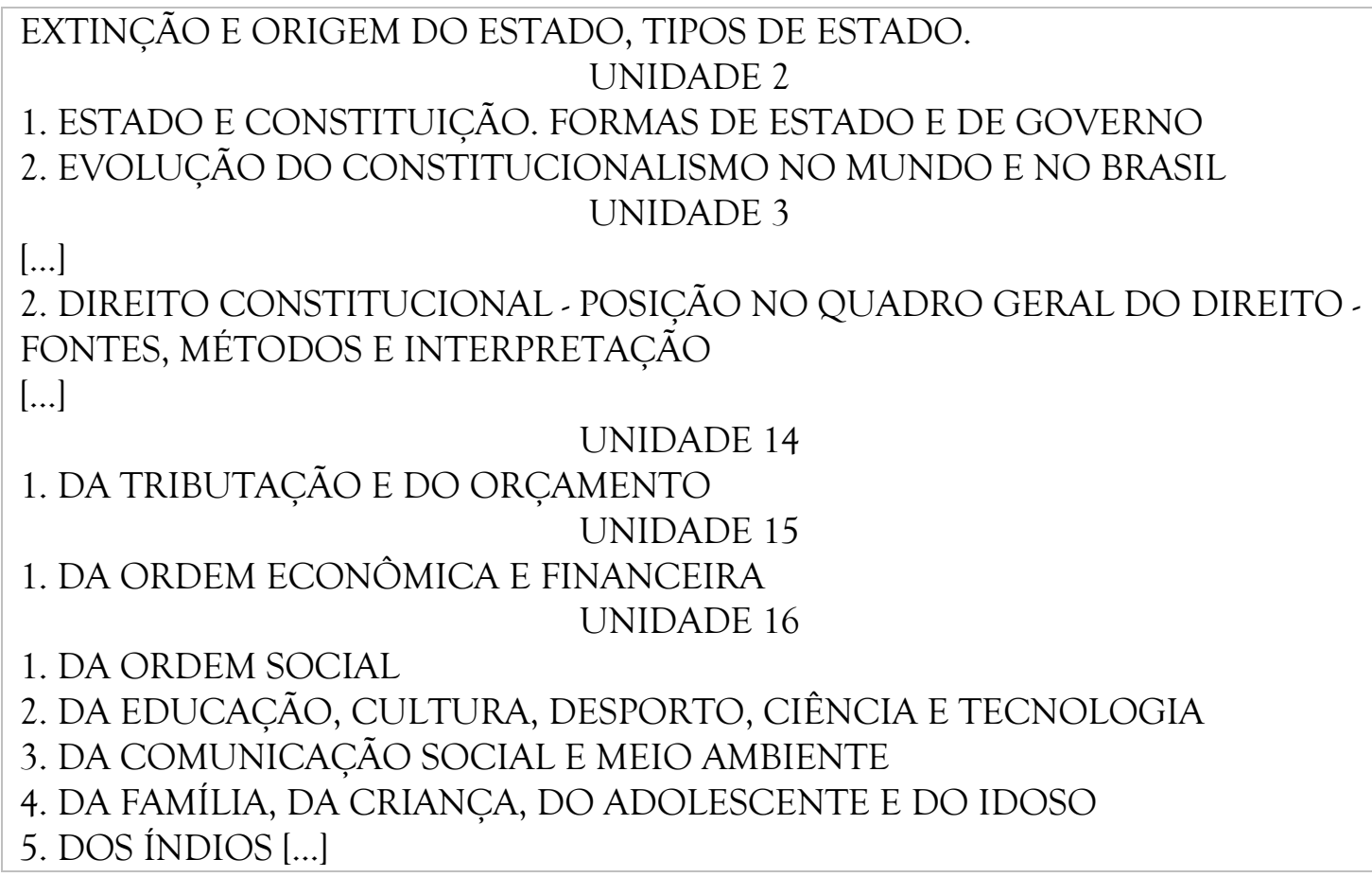

1. DA ORDEM SOCIAL

2. DA EDUCAÇÃO, CULTURA, DESPORTO, CIÊNCIA E TECNOLOGIA

3. DA COMUNICAÇÃO SOCIAL E MEIO AMBIENTE

4. DA FAMÍLIA, DA CRIANÇA, DO ADOLESCENTE E DO IDOSO

5. DOS ÍNDIOS [...]

O plano de estrutura e organização do processo pedagógico é o resultado da concepção fragmentária e positivista da realidade. Essa organicidade vai se expressar, de um lado, na infindável lista de disciplinas e de outro na divisão arbitrária entre disciplinas de conteúdo geral e humanista e disciplinas de conteúdo específico e técnico (FRIGOTTO, 1992).

Contudo ao analisar as bibliografias constatou-se uma quantidade maior de manuais doutrinários ${ }^{14}$ e apenas duas bibliografias "interdisciplinares", voltadas para a compreensão do aspecto Social e formação do Estado, porém não necessariamente isto signifique que a disciplina não dialogue com outras áreas do conhecimento, haja vista as inúmeras conexões possíveis ao longo do plano de ensino. Ficando materialmente limitada a atual análise, no qual só poderá ser melhor compreendida com a análise de sala de aula.

\section{DIREITO CONSTITUCIONAL}

\section{Bibliografia Básica}

BASTOS, Celso Ribeiro. Curso de direito constitucional / Celso Ribeiro Bastos. - São Paulo : Saraiva, 2001.

CANOTILHO, J. J. Gomes. Direito constitucional e teoria da constituição / J. J. Gomes Canotilho. - Coimbra : Almedina, 20-.

DALLARI, Dalmo de Abreu. A constituição na vida dos povos : da idade média ao século XXI / Dalmo de Abreu Dallari. - São Paulo : Saraiva, 2010.

DALLARI, Dalmo de Abreu. Constituição e constituinte. - São Paulo : Saraiva, 1986.

MENDES, Gilmar Ferreira. Curso de direito constitucional / Gilmar Ferreira Mendes, Inocêncio Màrtires Coelho, Paulo Gustavo Gonet Branco. - São Paulo : Saraiva, 2009.

\footnotetext{
${ }^{14}$ Obras básicas de referência.
} vol.09, n. 03, Rio de Janeiro, 2016. pp. 
BARROSO, Luís Roberto. Curso de direito constitucional contemporâneo : os conceitos fundamentais e a construção do novo modelo / Luís Roberto Barroso. São Paulo : Saraiva, 2010. MIGUEL, Jorge. Curso de direito constitucional / Jorge Miguel. - São Paulo : Atlas, 1989.

FERREIRA FILHO, Manoel Gonçalves. Curso de direito constitucional / Manoel Gonçalves Ferreira Filho. - São Paulo : Saraiva, 2012.

BONAVIDES, Paulo. Curso de direito constitucional / Paulo Bonavides. - São Paulo : Malheiros, 2013.

FERREIRA, Pinto. Curso de direito constitucional / Pinto Ferreira. - São Paulo : Saraiva, 2001. RUSSOMANO, Rosah. Curso de direito constitucional ,/ Rosah RUSSOMANO. - São Paulo : Saraiva, 1970.

BULOS, Uadi Lammêgo. Curso de direito constitucional / Uadi Lammêgo Bulos. - São Paulo : 2012.

SILVA, José Afonso da. Curso de constitucional positivo / José Afonso da Silva. - São Paulo : Malheiros, 2010.

\section{DIREITO CONSTITUCIONAL \\ Bibliografia Complementa}

BOBBIO, Noberto. Estado, governo, sociedade : para uma teoria geral da política / Noberto Bobbio; tradução Marco Aurelio Nogueira. - São Paulo : Paz e Terra, 1997.

DINIZ, Maria Helena. Norma constitucional e seus efeitos / Maria Helena Diniz. - São Paulo : Editora Saraiva, 2009.

LENZA, Pedro. Direito constitucional esquematizado / Pedro Lenza. - São Paulo : Saraiva, 2008. Curso de direito constitucional / Ricardo Cunha Chimenti ... [et al.]. - São Paulo : Saraiva, 2010. 
Quanto à disciplina Direito das Obrigações, não enunciou nenhuma forma de articulação da disciplina com outras e, das disciplinas analisadas, foi a que apresentou maior grau de rigidez interdisciplinar. Contudo destacou-se na ementa e no conteúdo uma alusão à Constituição.

\section{DIREITO DAS OBRIGAC̣ÕES \\ Ementa}

Constitucionalismo da relação obrigacional. Obrigações fontes.

Classificação e modalidades das obrigações. Adimplemento direto e indireto.

Transferência e cessão das obrigações.

Inexecução das obrigações. Inadimplemento. Cláusula Penal. Perdas e danos. Juros legais.

\section{DIREITO DAS OBRIGAÇÕES \\ Conteúdo \\ Introdução \\ Posição no Direito Civil \\ Marcos Conceituais \\ A evolução histórica.}

A historicidade presente no direito obrigacional.

Noção histórica de obrigação, evolução da teoria das obrigações, codificações e importância do direito obrigacional.

Pacta Sunt Servanda e sua crítica.

A visão do novel direito civil sobre o dogma da vontade.

$$
\text { Fontes }
$$

Elementos Constitutivos - Sujeitos, Objeto e Vínculo Jurídico

Natureza Jurídica da Obrigação

Constitucionalização das Relações Obrigacionais - dignidade da pessoa humana [...]

Apesar de possíveis conexões com os direitos humanos e interpretações jurisprudenciais, constatou-se uma abordagem maior ao direito civil positivado. Contudo, apesar desta aparente rigidez disciplinar, houve na bibliografia complementar uma referência à função social do contrato.

\section{DIREITO DAS OBRIGAÇÕES \\ Bibliografia Complementar}

NADER, Paulo. Curso de direito civil / Paulo Nader. - Rio de Janeiro : Forense, 2012.

RIZZARDO, Arnaldo. Contratos de crédito bancário / Arnaldo Rizzardo. - São Paulo : Ed.

Revista dos Tribunais, 2000.

THEODORO JÚNIOR, Humberto. O contrato e sua função social / Humberto Theodoro Júnior. - Rio de Janiero : Forense, 2008.

RODRIGUES, Silvio. Direito civil / Silvio Rodrigues. - São Paulo : Editora Saraiva, 2007 2008.

COELHO, Fábio Ulhoa. Curso de direito civil / Fábio Ulhoa Coelho. - São Paulo : Saraiva, 2010. 
Macedo e Lopes (2002) e Lopes (2008) asseveram que a organização sob a forma disciplinar é uma tecnologia de organização curricular que desenvolve mecanismos de regulação e controle da escola.

Por um simples quadro de horário escolar, são definidos e controlados os conteúdos a serem ensinados, as atividades de professores e de alunos, bem como o espaço e o tempo dessas atividades. A utilização da tecnologia de organização disciplinar, no entanto, não impede, ao longo da história do currículo, a organização de diferentes mecanismos de integração, seja pela criação de disciplinas integradas ou pela tentativa de articulação de disciplinas isoladas. (LOPES, 2008, p. 82).

\section{As práticas interdisciplinares}

As disciplinas práticas sorteadas foram Oficina de Prática Jurídica I e Prática Jurídica Social I, ambas as disciplinas são direcionadas para a integração entre prática e teoria. Contudo a disciplina de Prática Jurídica Social I vai além e idealiza a integração de teoria, prática e extensão numa disciplina na qual o aluno ficará disposto em grupos supervisionadas pelo professor, monitores e alunos mais antigos no escritório modelo. Assim ambas as disciplinas tem um caráter interdisciplinar, porém nenhuma das duas explicita isto nos respectivos planos de ensino.

Primeiramente a disciplina de Prática Jurídica Social I conta com uma ementa que atende ao objetivo da disciplina:

\section{PRÁTICA JURÍDICA SOCIAL I \\ Ementa}

Atendimento ao público para consultas, mediações, conciliações, ingresso de ações judiciais e extrajudiciais. Exercício de prática jurídica no âmbito dos Programas e Projetos de Extensão da Faculdade de Direito.

\section{PRÁTICA JURÍDICA SOCIAL I \\ Objetivo}

Proporcionar ao aluno formação prática, com desenvolvimento das competências e habilidades necessárias à atuação profissional.

O Estágio de Prática Jurídica Social deve proporcionar ao aluno a participação em situações reais vinculadas à sua área de formação, bem como o contato com a comunidade atendida. A observância ao Código de Ética e Disciplina das profissões jurídicas deve perpassar todas as atividades vinculadas a disciplina de Prática Jurídica Social

Percebeu-se uma tendência a interdisciplinaridade haja vista que a base da disciplina se 12001112 vol.09, nº. 03, Rio de Janeiro, 2016. pp. 
dá através dos conhecimentos adquiridos, e que ainda estão sendo adquiridos, de disciplinas cursadas ao longo do curso de direito, das três áreas destacadas: Propedêuticas, Dogmáticas e Práticas. Ao analisar a bibliografia constatou-se, tanto na bibliografia básica, quanto na complementar, referências de outras disciplinas capazes de auxiliar no desenvolvimento das atividades propostas.

\section{PRÁTICA JURÍDICA SOCIAL I Bibliografia Básica}

TOURINHO FILHO, Fernando da Costa. Pratica de processo penal / Fernando da Costa Tourinho Filho. - São Paulo: Editora Saraiva, 2011.

GRINOVER, Ada Pellegrini. As nulidades no processo penal / Ada Pellegrini Grinover, Anotnio Scarange Fernandes, Antonio Magalhaes Gomes Filho. - São Paulo : Ed. Revista dos Tribunais, 2001.

FUX, Luiz. A reforma do processo civil: comentários e analise critica da reforma infraconstitucional do poder judiciário e da reforma do CPC / Luiz FUZ. - Niterói, RJ: Impetus, 2006.

CASELA, Jose Erasmo. Manual de pratica forense: processo civil / cido e Silva. - São Paulo: Saraiva, 2008.

\section{PRÁTICA JURÍDICA SOCIAL I \\ Bibliografia Complementar}

SOUZA, Arthur César de. A decisão do juiz e a influência da mídia: ineficácia da prova divulgada pelos meios de comunicação para o processo penal e civil / Arthur César de Souza; apresentação Carlo Enrico Paliero, Néfi Cordeiro. - São Paulo: Ed. Revista dos Tribunais, 2010.

A disciplina Oficina de Prática Jurídica I também apresentou bibliografias que tradicionalmente são empregadas em outras disciplinas, de maneira que, apesar de não elucidar nenhuma prática de articulação disciplinar, pode ser um que na prática pedagógica se encontre indícios de interdisciplinaridade.

\section{OFICINA DE PRÁTICA JURÍDICA I Bibliografia Básica}

VADE MECUM / Organizador: Nylson Paim de Abreu Filho. - Porto Alegre: Verbo Jurídico, 2010.

MARINONI, Luiz Guilherme. Curso de processo civil / Luiz Guilherme Marinoni, Sergio Cruz Arenhart. - São Paulo : Ed. Revista dos Tribunais, 2006 - 2007.

MARINONI, Luiz Guilherme. Curso de processo civil / Luiz Guilherme Marinoni, Sergio Cruz Arenhart. - São Paulo : Ed. Revista dos Tribunais, 2012.

TARTUCE, Fernanda. Manual de prática civil / Fernanda Tartuce, Luiz Dellore, Marco Aurelio Marin; coordenação Vauledir Ribeiro Santos. - São Paulo : Método, 2012.

Fazenda (1992b), em outra obra que trata sobre o tema da interdisciplinaridade, sustenta 
que o fato de o termo integração ser basicamente introduzido para designar o estabelecimento de uma hierarquia dos conteúdos das matérias, seja na busca da ordenação horizontal ou vertical, poderia levar a uma caracterização de multi ou pluridisciplinaridade, em que a preocupação primeira seria com a justaposição de conteúdos de disciplinas heterogêneas, ou, a integração de conteúdos de uma mesma disciplina. O termo interdisciplinaridade é tomado apenas como meio para se atingir essa integração, A integração seria então efetivamente o produto final e não etapa para a interdisciplinaridade, cuja tônica principal seria a "interação" e cujo objetivo final seria o estabelecimento de uma atitude dialógica tendo-se em vista a compreensão e a modificação da própria realidade. (FAZENDA, 1992b, p. 83).

Cumpre esclarecer que, paralelamente ao conceito de interdisciplinaridade, outros três se construíram: de multidisciplinaridade, de pluridisciplinaridade e de transdisciplinaridade.

La transdisciplinarité est un état d'équilibre total entre l'influence de toutes les disciplines en cause, au niveau le plus élevé de coordination. Dans le sens où ce mot est employé ici, la coordination implique des contacts ou une communication optimisés. La portée et la qualité de la coopération sont telles qu'une nouvelle discipline peut Etre créée du point de vue analytique et social. La pluridisciplinarité est caractérisée par le fait que la communication s'exerce entre divers milieux ou disciplines, et la communication est symétrique. L'aspect qualitatif s'améliore dans la mesure où l'influence sur un projet d'enseignement ou de recherche determiné s'exerce de façon plus équilibrée. La multidisciplinarité est la forme la moins développée d'interdisciplinarité. La communication entre les divers milieux est réduite au minimum. Cependant, il est fréquent que les projets d'enseignement ou de recherche se chevauchent ou soient complémentaires Il pourrait donc être utile, dans un premier temps, de juxtaposer certains éléments de diverses disciplines afin de mettre em lumière leurs aspects communs.15 (UNESCO, 1986, p. 06-07).

Semelhantes conceitos são adotados por investigadores brasileiros.

No primeiro nível (multidisciplinar16), as disciplinas ou especialidades encontram-se isoladas. Temos um bom exemplo disso naqueles currículos compostos por matérias/disciplinas que se justapõem, mas praticamente não "conversam" entre si. No segundo nível, o da pluridisciplinaridade, as matérias/disciplinas trocariam conhecimentos, experiências, metodologias entre si, isto é, "conversariam" sem, no entanto, chegarem a criar um novo

\footnotetext{
15 Em tradução livre: "A transdisciplinaridade é um estado de equilíbrio total de influência de todas as disciplinas envolvidas, no mais alto nível de coordenação. No sentido em que esta palavra é aqui usada, a coordenação envolve o contato ou comunicação otimizada. $\mathrm{O}$ alcance e a qualidade da cooperação são tal qual uma nova disciplina, pode ser criada do ponto de vista analítico e social. A pluridisciplinaridade é caracterizada pelo fato de que a comunicação se realiza entre os diferentes meios ou disciplinas, e a comunicação é simétrica. $\mathrm{O}$ aspecto qualitativo é melhorado na medida em que influencia um projeto de ensino ou de pesquisa determinando sua execução de maneira mais equilibrada. A multidisciplinaridade é a forma menos desenvolvida de interdisciplinaridade. A comunicação entre os diferentes ambientes é minimizada. No entanto, é comum que os projetos educacionais ou de pesquisa se sobreponham ou sejam complementares. Portanto, pode ser útil como um primeiro passo, o de justapor certos elementos de várias disciplinas, a fim de colocar luz sobre os aspectos comuns."

${ }^{16}$ Expressão adicionada pelo autor.
} vol.09, nº. 03, Rio de Janeiro, 2016. pp. 
conhecimento fora delas. No terceiro nível, o interdisciplinar, haveria uma integração bem maior entre as diferentes matérias/disciplinas, a ponto de se estabelecer um novo nível de conhecimentos, qual um guarda-chuva que teria sob si os níveis que lhe deram origem. [...] O último nível, o transdisciplinar, seria aquele em que acontece uma verdadeira fusão disciplinar; tudo se misturaria e não se conseguiria mais identificar os limites entre as antigas disciplinas. (VEIGA-NETO, 1995, p. 109).

Tendo em conta a presente investigação, nestes primeiros dados analisados, é possível afirmar que não há relação interdisciplinar na grade bibliográfica. Estes são achados iniciais de pesquisa. É necessário que estes dados sejam confrontados quando da análise das mensagens sociológicas de sala de aula ou mesmo nas entrevistas, para se saber em qual grau ou direção atendem a interdisciplinaridade. No entanto, quando se refere comparativamente às disciplinas do eixo prático, especialmente se comparadas ao do tronco profissional, como Direito Constitucional.

\section{CONSIDERAÇÕES FINAIS}

Apesar de apenas uma disciplina estar perfeitamente de acordo com o Parecer CES/CNE no 146/02, a Resolução CES/CNE n 09/04 e com o Plano Político Pedagógico, constatou-se que alguns planos de ensino foram capazes de realizar a interdisciplinaridade ou até mesmo estabelecer diálogos significativos e transformadores, seja internamente entre disciplinas do currículo jurídico ou externamente com outros campos do conhecimento. Importa esclarecer que, tanto para Beane (2003 e 2010), como para Bernstein $(1996,1998)$ o conceito de integração não se confunde com o de interdisciplinaridade. Naquele, a integração possui íntima relação às experiências vivenciadas pelos alunos e que podem, de algum modo, ser integradas quando da transmissão do conhecimento, através de modalidades de práticas pedagógicas específicas, "o que estamos aqui a abordar é uma concepção de currículo que procura relações em todas as direcções” (BEANE, 2003, p. 94). Já em Bernstein (1996, 1998), a integração se traduz em vários conteúdos que estão diretamente subordinados a uma ideia centralizadora que reduz o isolamento entre eles e os agrega em um todo mais amplo.

Bernstein (1996) sustenta que cada conteúdo deixa de ter uma significação individual (absoluta) para, então, assumir uma importância relativa e passar a ter uma função bem determinada e explícita dentro do conjunto. Ainda, segundo Bernstein, a integração (total) somente existirá em nível ideológico e da teoria.

Na medida em que o conhecimento, em um currículo integrado, está organizado em conteúdos abertos que se inter-relacionam em torno de uma ideia central, urge uma prática 
pedagógica que permita essa comunicação. Esse parece ser um dos grandes desafios dessas propostas, mesmo as tendentemente integradoras.

Entende-se que os processos educativos objetivam a minimização das desigualdades e, no campo jurídico, elas se operam na formação de profissionais que reconheçam a cidadania e a justiça social como base de um direito emancipatório, no qual a dignidade, a solidariedade, a justiça social e os direitos humanos estejam relacionados com o ensino jurídico, em prol de uma formação crítica, reflexiva e da transformação social (WARAT, 2004). Todavia não basta modificar ou "recriar" os currículos, mas repensar a estrutura com a qualificação do quadro docente das Faculdades de Direito, almejar um currículo integrado, inserindo gradativamente a interdisciplinaridade, sobretudo, nos conteúdos tradicionalmente jurídicos.

Importante dizer que a base da abordagem interdisciplinar distingue, também, uma atitude ética que pode ser chamada de "dialógica". Sem renunciar a sua própria identidade, os protagonistas envolvidos na produção do trabalho científico adotam um debate cooperativo em que a pesquisa prevalece. De uma forma relacional, cada envolvido ouve a posição do outro. Assim, o diálogo interdisciplinar convida as múltiplas convicções a discutirem e firmarem um compromisso de diálogo para uma busca coletiva da verdade, supondo que a diversidade de opiniões e a incerteza dos resultados é uma forma ética de produção do conhecimento.

\title{
INTERDISCIPLINARY IN THE LAW SCHOOL CURRICULUM: A CASE STUDY
}

\begin{abstract}
This research is a fragment of a larger proposal to understand the daily life of the Law School of a Public University of the South. In this sense, the research involves an empirical fact-finding stage of sociological messages expressed in the classroom, through qualitative instruments and interview applied to teachers of this course. For this article we tried to discuss the interdisciplinarity in a legal curriculum through their teaching plans. Were analyzed six subjects, chosen by lottery, distributed in three areas: propaedeutic, dogmatic and practices in order to classify them according to the multi-level, inter- or transdisciplinary promoted by the elements expressed in the curriculum documents.
\end{abstract}

Keywords: Interdisciplinary; Curriculum integration; Legal education: Curriculum.

\section{REFERENNCIAS}

BALL, Stephen J. Education reform: a critical and post-structural approach. Buckingham: Open University Press, 1994. 
BEANE, James A. Integração curricular: a essência de uma escola democrática. Currículo sem fronteiras. V. $3 . \quad$ n. 2, p. 91-110. Jul/dez. 2003. In: http://www.curriculosemfronteiras.org/vol3iss2articles/beane.pdf. < Acesso em 12 de setembro de 2015>.

BERNSTEIN, Basil. Class, Codes and Control, Vol. III, second (revised) edition, London: Routledge, 1977.

BERNSTEIN, Basil. Pedagogia visível e invisível. In: Cadernos de Pesquisa (29), p. 26-42. São Paulo, 1984.

BERNSTEIN, Basil. Class, codes and Control, Vol. IV: The structuring of pedagogic discourse. London: Routledge, 1990a.

Poder, Educación y Conciencia. Sociología de La Transmisión cultural. Barcelona, España: El Roure Editorial, 1990b. 1996.

A estruturação do discurso pedagógico: classe, códigos e controle. Petrópolis, RJ: Vozes,

Pedagogía, Control Simbólico e Identidad. Madrid, Espanã: Ediciones Morata, 1998.

Vertical and horizontal discourse: an essay. British Journal of Education, v. 20, n. 2, p. 157-173, London, UK, 1999.

Pedagogy, symbolic control and identity: Theory, research, critique. Londres: Rowman \& Littlefield, 2000.

Pedagogização do conhecimento. Estudos sobre recontextualização. Cadernos de Pesquisa n.120, p. 75-110, São Paulo,2003

BOGDAN, Robert. C: BIKLEN, Sari Knopp. Investigação qualitativa em educação: uma introdução à teoria e aos métodos. Porto: Porto Editora, 1994.

BRASIL. Resolução do Conselho Nacional de Educação - Câmara de Educação Superior n. 09, de 27 de setembro de 2004. Institui as diretrizes curriculares nacionais do Curso de Graduação em Direito e dá outras providências. Disponível em: http://portal.mec.gov.br/cne/arquivos/pdf/rces09_04.pdf. < acesso em 11.04.2015>.

DIAS, Renato Duro. Relações de poder e controle no currículo do curso de direito da FURG. Tese de Doutorado. Programa de Pós-Graduação em Educação, Universidade Federal de Pelotas. Pelotas, UFPEL, 2014.

FAZENDA, Ivani C. A. Integração e interdisciplinaridade no ensino brasileiro: efetividade ou ideologia? São Paulo: Loyola, 1992.

FRIGOTTO, Gaudêncio. A interdisciplinaridade como necessidade e como nas ciências sociais. In: Seminário de Educação/92 - Interdisciplinaridade - o pensado, o vivido. Cuiabá: UFMT, 1992.

JAPIASSÚ, Hilton. Interdisciplinaridade e patologia do saber. Rio de Janeiro: Imago, 1976.

LAKATOS, E. M.; MARCONI, M. de A. Fundamentos de metodológica científica. 3. ed. rev. e ampl. São Paulo: Atlas, 1993. 
LOPES, Alice Casemiro. Políticas de integração curricular. Rio de Janeiro: EdUERJ, 2008.

RODRIGUES, Horácio Wanderlei. Pensando o Ensino do Direito no Século XXI. Florianópolis: Fundação Boiteux, 2005.

SANTOS, Boaventura de Sousa. A crítica da razão indolente: contra o desperdício da experiência. Para um novo senso comum. A ciência, o direito e a política na transição paradigmática. V. 1. São Paulo, Cortez Editora, 2000. 2005.

Pela mão de Alice. O social e o político na pós-modernidade. 10 ed. São Paulo, Cortez,

UNIVERSIDADE FEDERAL DO RIO GRANDE. Curso de Direito. Projeto Político Pedagógico. Rio Grande, RS, FURG, 2012.

VEIGA-NETO, Alfredo J. Currículo, disciplina e interdisciplinaridade. Ideias - Revista da Fundação Para o Desenvolvimento da Educação, São Paulo, n. 26, p. 105-119, 1995.

De geometrias, currículos e diferenças. Educação \& Sociedade, ano XXIII, no 79, agosto, Campinas, SP, 2002.

WARAT, Luis Alberto. Epistemologia e ensino do direito: o sonho acabou. Coordenadores Orides Mezzaroba, Arno Dal Ri Júnior, Aires José Rover e Cláudia Servilha Monteiro. Florianópolis: Fundação Boiteux, 2004.

Trabalho enviado em 19 de dezembro de 2015.

Aceito em 24 de março de 2016. 